\title{
The Dirty Dozen Cleaning Products at Home
}

\author{
Derrick A Balladin* \\ University of Trinidad and Tobago, O'Meara Campus, Trinidad and Tobago
}

Submission: May 19, 2020; Published: June 05, 2020

*Corresponding author: Derrick A Balladin, University of Trinidad and Tobago, O’Meara Campus, Arima, Trinidad and Tobago

\section{Abstract}

In today's world, it's practically impossible to reduce the exposure of all cleaning products at home, but one can significantly reduce the levels and duration exposure. This paper seeks to highlight "The Dirty Dozen Cleaning Products at Home", although the entire list is very comprehensive, the focus will be on this selected suite: Air Fresheners; Ammonia; Bleach; Carpet and Upholstery Shampoos; Dishwasher Detergents; Drain Cleaners; Furniture Polish; Mold and Mildew Cleaners; Oven Cleaner; Antibacterial Cleaners; Laundry Room Products; and Toilet Bowl Cleaners. Highlighting some of the many ills and toxic chemicals which make up these "necessary" household commodities for a safe and clean home.

Keywords: Cleaning products at home

\section{Introduction}

"All things are poisons, for there is nothing without poisonous qualities. It is only the dose which makes a thing poison." Philippus Aureolus Theophrastus Bombastus von Hohenheim, also known as Paracelsus [1].

Most cleaning products at home contain a cocktail of toxic substances that can completely "destroy" your family wellbeing. As stated by the Environmental Working Group [2] (an American environmental organization that focuses on the research and advocacy of toxic chemicals), household cleaners lack safety guidelines. As a consequence, companies are not mandated to provide Safety Data Sheets, which provides the avenue for a total lack of consumer protection. These harmful substances contained in these products, should not be overlooked, since, by aggressive advertising, these manufacturing companies may suggest that the constant use of these dangerous household cleaning products are needed to have your home constantly sanitized, scrubbed, and cleaned, all to protect your family's health.

An average household cleaning product may have greater than 62 (or more) toxic cleaning chemicals, unknown to the consumer [3]. How sarcastic is the cry that these household cleaners are "necessary" to keep us sanitized from harmful microorganisms but they have been compounded from a suite of deadly toxins. It is normally stated, that the active compounds (which are usually very toxic) are added in very small amounts, hence in there lies its safety, but no mentioned about the bioaccumulative effects generated from repeated use of these products. Bioaccumulation is the accumulation of substances, such as toxins from household cleaners in a human or animal, at a faster rate than it is removed via excretion.

There is also the synergistic effect which is an effect arising from the components of the household cleaners, which produces an effect greater than the sum of their individual toxic effects Conversely, there is also the antagonistic effects which have the opposite destructive effects (e.g. Sodium and chlorine are two very dangerous chemicals, however, when mixed in the correct ratio, produces common sodium chloride (table salt).

\section{Types of Toxic Household Cleaners}

Everyday household cleaners containing toxic chemicals may vary in their severity - from acute (instant) hazards such as skin or respiratory issues, allergies, chemical burns to chronic (long-term) hazards such as cancer, fertility issues, cardiovascular diseases, Attention Deficit Hyperactivity Disorder and compromised immune system.

The major active ingredients which are toxic chemicals found in household cleaners fall into these categories (Figure 1):

This paper seeks to highlight "The Dirty Dozen Cleaning Products at Home", although the entire list is very comprehensive, the focus will be on this selected suite: Air Fresheners; Ammonia; Bleach; Carpet and Upholstery Shampoos; Dishwasher Detergents; Drain Cleaners; Furniture Polish; Mold and Mildew Cleaners; Oven Cleaner; Antibacterial Cleaners; Laundry Room Products; and Toilet Bowl Cleaners. 


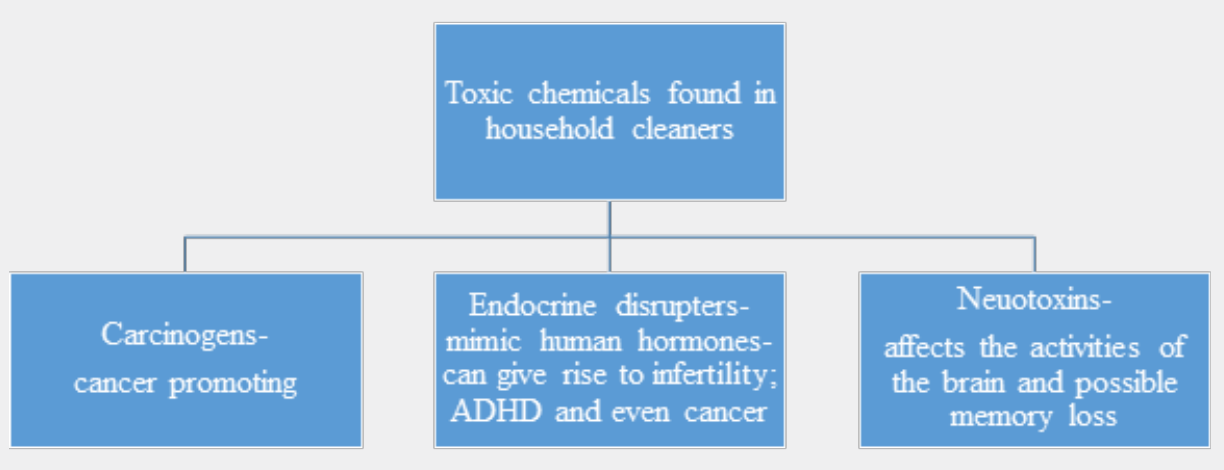

Figure 1: Toxic chemicals found in household cleaners.

\section{Air fresheners}

Be consumer smart; do not get caught by the modern advertising and sale pitch [4]. Three major toxic chemicals found in air fresheners are

(i) formaldehyde (this hydrocarbon $\left(\mathrm{CH}_{2} \mathrm{O}\right)$ is extremely toxic and a known carcinogen. Once inhaled, formaldehyde which is very water soluble is quickly absorbed, in the nasal and respiratory tract) and

(ii) phenol $\left(\mathrm{C}_{6} \mathrm{H}_{5} \mathrm{OH}\right)$ \{which can cause allergies, hives or rashes, respiratory diseases, coma, and even death\}.

The fragrances present in Air Fresheners can activate asthma and allergies. It was cited by the Environmental Working Group (EWG) who investigated 2,000 household cleaning products in 2012 , highlighted that $53 \%$ of those cleaning products contain ingredients harmful to the respiratory tract and $22 \%$ of cleaning products contain chemicals known to cause asthma. Steinemann [5], cited that Air Fresheners may contain the following toxic chemicals: acetaldehyde; acetone; camphor; ethanol; benzaldehyde; isopropyl alcohol; pinene; benzyl acetate; ethyl acetate; isoamyl acetate (1-butanol, 3-methyl-, acetate); limonene; linalool ;5-methyl-3-heptanone (ethyl sec-amyl ketone); tertbutyl alcohol; methanol; methyl benzoate; phthalates. With most listed as Suspected Developmental, Endocrine, Gastrointestinal or Liver, Kidney, Neurotoxicant, Reproductive, Respiratory and Skin or Sense Organ Toxicants [5].

\section{Ammonia}

$\left(\mathrm{NH}_{3}\right)$ is one of the most commonly produced industrial chemicals in the United States by the Haber process (combines nitrogen $\left(\mathrm{N}_{2}\right)$ from the atmosphere with hydrogen $\left(\mathrm{H}_{2}\right)$ mainly from natural gas (methane) into ammonia). At room temperature, ammonia is a colorless, highly irritating volatile gas with a pungent, suffocating odor. Household ammonia cleaning solutions are produced by adding ammonia gas to water, resulting in a solution between $5 \%(\mathrm{v} / \mathrm{v})$ to $10 \%(\mathrm{v} / \mathrm{v})$ ammonia. However, for industrial ammonia solutions may be as high as $25 \%(\mathrm{v} / \mathrm{v})$ or higher. Toxic ammonium hydroxide is formed between the moisture in the skin, eyes, oral cavity, and respiratory tract and the ammonia from the cleaners [6].

Due to the normal child's proximity to the floors with respect to adults, children are affected to a greater extent, since the concentrated stratified ammonia vapors linger at ground level as stated by New York State Department of Health [7].

Low concentrations of ammonia in the atmosphere or in solution may result in skin or eye irritation. At higher concentrations may cause severe injuries such as permanent eye damage or blindness and burns. In addition, swallowing concentrated ammonia solution will cause corrosive damage to the mouth, throat, and stomach.

\section{Bleach}

Bleach is used to whiten clothes, remove stains and also a disinfectant in the bathroom and kitchen. Chlorine is the main active ingredient in the sodium hypochlorite $\left(\mathrm{NaOCl}_{3}-6 \% \mathrm{v} / \mathrm{v}\right)$ solution, which is so ubiquitous that most people refer to it as "bleach". It is produced by bubbling chlorine gas through a dilute sodium hydroxide solution

$$
\mathrm{Cl}_{2(\mathrm{~g})}+2 \mathrm{NaOH}_{(\mathrm{aq})} \rightarrow \mathrm{NaCl}_{(\mathrm{aq})}+\mathrm{NaOCl}_{(\mathrm{aq})}+\mathrm{H}_{2} \mathrm{O}_{(\mathrm{l})}
$$

Bleach must never be mixed with ammonia, acids, or other cleaners since this can cause serious injuries. In addition, bleach ingestion can cause irreversible damage to the esophagus and stomach, which can eventually lead to death. Contact with the skin, it will cause irritation and a soapy feeling. Bleach splashed in the eyes may cause permanent damage. Lung damage can occur from inhalation of bleach fumes. It was reported by OSHA [6] that "chlorine is a respiratory irritant that attacks mucous membranes and burns the skin. A detectable odour of 3.53ppm is noticeable, and at 1000ppm can be fatal after a few deep breaths. Exposure to chlorine has been limited to a value of 0.5ppm (8-hour timeweighted average-38-hour week)." 
Mixing Bleach with other chemicals such as:

(i) Ammonia produces toxic gases called chloramines extensive exposure to chloramine gases can cause the following symptoms: Coughing; Nausea; Shortness of breath; Watery eyes; Chest pain; Irritation to the throat, nose, and eyes; Wheezing.

(ii) Pneumonia and fluid in the lungs, symptoms many people experienced while cleaning bathrooms with these cocktails.

Acids when mixed with chlorine bleach, chlorine gas is liberated as shown below

$\mathrm{NaOCl}+\mathrm{H}_{2} \mathrm{O} \leftrightarrow \mathrm{HOCl}+\mathrm{Na}^{+}+\mathrm{OH}^{-}$

sodium hypochlorite $\leftrightarrow$ hypochlorous acid

$\mathrm{HOCl}+\mathrm{H}^{+} \leftrightarrow \mathrm{H}_{2} \mathrm{O}+\mathrm{Cl}_{2}$

hypochlorous acid + acid (from vinegar, toilet bowl cleaners etc.) $\leftrightarrow$ water + chlorine gas

Short periods of time and at low concentrations exposure to $\mathrm{Cl}_{2}$ gas exposure, can irritates the mucous membranes (eyes, throat, and nose), and causes coughing and breathing problems, runny nose, burning and watery eyes. At higher concentrations exposure, $\mathrm{Cl}_{2}$ can cause chest pain, more severe breathing difficulties, vomiting, pneumonia, and fluid in the lungs and eventually death [8].

Many of the residents cleaned they flooded homes with bleach, this was a very dangerous practice, since the chlorine gas from the bleach will react with the organic compounds (for example methane which may be present in the flood waters) to form trihalomethanes (disinfection by-products, which can cause cancer or classed as a mutagen).

\section{Carpet and upholstery shampoos}

Produces more toxic dangers than vacuuming. Generally these cleaning products contain highly toxic substances like

(i) Perchloroethylene $\left(\mathrm{C}_{2} \mathrm{Cl}_{4}\right)$ which is a colorless, nonflammable liquid with a sweet, ether-like odor (dry cleaning liquids), it is also a documented carcinogen that damages the liver, kidneys, and nervous system and

(ii) Ammonium hydroxide (a corrosive that irritates eyes, skin, and respiratory passages).

\section{Dishwasher detergents}

It is used extensively by most people. The major brands of dishwasher detergents are made from sulfonic acid (a hydrocarbon) and other highly toxic substances. These can cause hormonal disruptions, lung and eye irritations, intoxication and cancer. Although the following toxic ingredients are usually in small amounts in commercial dish detergents, over time, they have the potential accumulate effect to cause long-term health issues.
Ammonia; Coal Tar Dyes; Cocamide DEA; Chlorine bleach; DEA (diethanolamine), MEA (monoethanolamine), TEA (triethanolamine); Formaldehyde; Fragrance (a mixture of over 3000 toxic chemicals); Glycol ethers; Phosphates; Triclosan (antibacterial); and Sodium Borate [9].

\section{Drain cleaners}

It may use sodium hydroxide (caustic soda or lye- can burn skin and eyes, and the esophagus and stomach if ingested) or sulfuric acid (a highly corrosive eye and skin irritant that damages kidneys, liver, and digestive tract, also found in automobile batteries) and trichloroethane (toxic eye and skin irritant and nervous system depressant). These are extremely corrosive to organic materials and many metals. The main action of a drain cleaner will quickly clear a clog plumbing system, but it can also burn your clothes and skin

\section{Furniture polish}

It is widely used in the home especially around Christmas time. To bring home that joyous feeling, one must smell furniture polish and fresh paint. However there are numerous toxic chemicals present in furniture polish as stated by Scutti (2013)- Phthalates (affected the reproductive system of laboratory animals); Volatile Organic Compounds (VOCs- cause damage to the liver, kidney, and central nervous system and carcinogenic); polybrominated diphenyl ethers (PBDEs)- includes pentabromodiphenyl ether (c-pentaBDE), octabromodiphenyl ether (c-octaBDE), and decabromodiphenyl ether (c-decaBDE); Perfluorinated compounds (PFCs)- affect growth and development, reproduction, and function of the liver; Perchloroethylene (PCE)- acute effects-, can cause dizziness and unconsciousness; chronic exposure can cause liver and kidney damage, memory loss, confusion, and even cancer; Formaldehyde- The National Cancer Institute states that research links formaldehyde exposure to several cancers, including nasopharyngeal cancer and leukemia; Triclosanantibacterial; chlorine and ammonia; and cresols and petroleum distillates, which are toxic chemicals that can cause skin and eye irritation, along with central nervous system damage [10].

\section{Mold and mildew cleaners}

Mold and Mildew Cleaners are a mixture of water and sodium hypochlorite (a corrosive and highly toxic liquid which can lead to fluid in the lungs - bleach), and other active ingredients such as butyl cellosolve (with their inherent toxic danger to the respiratory system). Some cleaners may contain pesticides; Fragrance (a mixture of over 3000 toxic chemicals); and formaldehyde (a highly toxic, and known carcinogen).

\section{Oven cleaner}

It contains lye (sodium hydroxide), sometimes more commonly referred to as caustic soda. If it comes into contact with your skin or eyes, it's very dangerous and causes very severe burns and blindness. Inhalation of lye will cause a sore throat 
and coughing that persists for days, prolonged exposure can cause severe damage to the nostrils and lungs, and in some cases permanent damage.

\section{Antibacterial cleaners}

As the name suggests they remove bacteria which can cause some very unsavory diseases such as tuberculosis, cholera, pneumonia, food poisoning, strep throat, and meningitis. Hygiene plays a pivotal role in curbing the spread of bacterial infections. Active ingredients such as triclosan have been linked to liver damage when absorbed through the skin. Antibacterial soaps may also contribute to the development of drug-resistant bacteria.

\section{Laundry room products}

It may not be good for our health as one investigates the manufacturers' active and filler ingredients. They may include Fragrance; Cleaning agents (surfactants); Stabilizers; Bleach; 1,4-dioxane; Brighteners \{ naphthotriazolystilbenes (linked with developmental and reproductive effects), benzoxazolyl, and diaminostilbene disulfonate\}; and Phosphates \& EDTA (ethylene diamine tetraacetic acid). All these chemicals can be very dangerous based on the exposed dosage [11].

\section{Toilet bowl cleaners}

It may contain many corrosive ingredients which are severe eye, skin and respiratory irritants. Some toilet bowl cleaners may contain sulfates, which can initiate asthma attacks, irritation of lungs and burn eyes, skin when these cleaners are combined with other cleaners containing sodium hydroxide, sodium hypochlorite (bleach), phosphoric acid. If ingested, internal organs failure. Mixing acid-containing toilet bowl cleaners with other cleaners which may contain chlorine can produce lung-damaging chlorine [12].

\section{Conclusion}

Adoption of the "Precautionary Principle" according to the Science and Environmental Health Network [13], should be the approach to handle toxic cleaning products at home. As the old adage goes "Better safe than sorry". As shown, the dirty dozen cleaning products at home are very toxic and in most cases bioaccumulative, which can cause acute and chronic effects.

Remember when handling dangerous and toxic chemicals, Personal Protective Equipment MUST be worn.

\section{References}

1. Paracelsus: the Father of Toxicology and the Enemy of Physicians.

2. Environmental Working Group - Wikipedia.

3. Top 8 Dangerously Toxic Cleaning Chemicals to Avoid - Natural ON.

4. How Air Fresheners Are Killing You - The Health Wyze Report.

5. (2013) Toxic Chemicals in Air "Fresheners" and Health Effects. In: Steinemann AC, Professor, Civil and Environmental Engineering, and Public Affairs, University of Washington. National Institutes of Health, Environmental Protection Agency.

6. Occupational Safety \& Health Administration (2007) and peroxide/ recognition.html "OSHA - Chlorine" OSHA.

7. The Facts About Ammonia - New York State Department of Health.

8. Bleach Mixing Dangers: Washington State Department of Health.

9. EPA (2014) The greatest exposure to toxic chemicals is right inside our own. The Harmful Ingredients Found in Commercial Dish Detergents.

10. Nine Toxic Chemicals Found In Furniture: Is Your Home A Hazard Zone?.

11. Gianni A (2017) Seven Toxic Chemicals in Laundry Detergent.

12. How Toxic Are Your Household Cleaning Supplies? 2017 Organic Consumers Association.

13. The dirty truth about cleaning products.

Your next submission with Juniper Publishers will reach you the below assets

- Quality Editorial service

- Swift Peer Review

- Reprints availability

- E-prints Service

- Manuscript Podcast for convenient understanding

- Global attainment for your research

- Manuscript accessibility in different formats

( Pdf, E-pub, Full Text, Audio)

- Unceasing customer service

Track the below URL for one-step submission https://juniperpublishers.com/online-submission.php 